\title{
萗氧桥香豆素-双核锌酞菁的合成与性能研究
}

\author{
曹杰翏超强杨玲张学俊* \\ (中北大学理学院 太原 030051)
}

\begin{abstract}
摘要 以 1,5 -二羟基菜、4-硝基邻苯二甲腈、间苯二酚、乙酰乙酸乙酯以及醋酸锌为主要原料, 合成了 9(10),16(17),23(24)-三[4-甲基-7-香豆素氧基]-2(3)-(1,5-二氧基菜)双核锌酞菁(bi-CPc). 利用 ${ }^{1} \mathrm{H}$ NMR、FT-IR、UV-Vis、 元素分析、热重分析等手段对前驱体和 bi-CPc 的结构和性能进行 表征. 结果表明, bi-CPc 的紫外可见吸收光谱表现出 强烈的 $\pi-\pi^{*}$ 跃迁且在 $N, N-$ 二甲基甲酰胺(DMF)溶液中以单体形式存在, 并且具有良好的热稳定性. 用循环伏安法研究 了 bi-CPc 的氧化还原行为, 计算其 LUMO 和 HOMO 能级与纳米 $\mathrm{TiO}_{2}$ 能级匹配. 通过进一步结构修饰, 有望作为性能 良好的光敏染料用于太阳能电池.
\end{abstract}

关键词 酞菁; 双核; 香豆素; 染料敏化太阳能电池

\section{Synthesis and Characterization of the Coumarin-Binuclear Zinc Phthalocyanine Formed by Droxynaphthyl Bridge}

\author{
Cao, Jie Liao, Chaoqiang Yang, Ling Zhang, Xuejun* \\ (College of Science, North University of China, Taiyuan 030051)
}

\begin{abstract}
Tris[4-methyl-coumarin-7-yloxy]-2(3)-(1,5-naphthalene) binuclear zinc phthalocyanine (bi-CPc) based 1,5-dihydroxynaphthalene, 4-nitro-phthalonitrile, resorcinol, ethyl acetoacetate and zinc acetate on raw material was synthesized. The structures and properties of precursors and bi-CPc were characterized by ${ }^{1} \mathrm{H}$ NMR, FT-IR, UV-Vis, elemental analysis and thermogravimetric analysis. Results showed that strong $\pi-\pi^{*}$ transition was demonstrated by UV-Vis absorption spectrum of bi-CPc. At the same time, it existed in a form of monomer in solution of $N, N$-dimethylformamide (DMF) and possessed excellent thermal stability. Redox behavior of bi-CPc was researched by cyclic voltammetry (CV), and energy level of LUMO and HOMO of bi-CPc matched with energy level of nano- $\mathrm{TiO}_{2}$ after calculating. Through further structural modification, it is expected to use as photosensitive dye with excellent performance for solar cells.
\end{abstract}

Keywords phthalocyanine; binuclear; coumarin; dye-sensitized solar cells

染料敏化太阳能电池(DSSC)主要由染料敏化剂、纳 米多孔氧化物、电解质及阴极构成 ${ }^{[1]}$, 这种电池由于制 作工艺简单, 环境友好且成本较低, 引起了研究者的广 泛关注. 其中染料敏化剂是染料敏化太阳能电池 (DSSC) 的关键材料, 目前所研究的有机染料敏化剂主 要有多吡啶钓化合物、纯有机类以及卟啉和酞菁类染料 等 $[2,3]$. 多吡啶钓化合物具有良好的可见光谱响应和较 高的光电转换效率, 但是由于其成本较高和重金属毒性 较强而影响它的发展和应用 ${ }^{[4]}$. 纯有机类染料如二氢吲

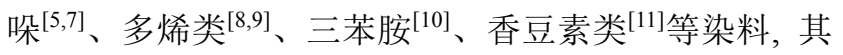
吸光系数高, 成本低, 但是其稳定性较差, 光电转换效
率有待提高. 卟啉类染料在 $400 \sim 450 \mathrm{~nm}$ 处有吸收较强 的 Soret 带, 在 $550 \sim 600 \mathrm{~nm}$ 处有中等吸收强度的 $\mathrm{Q}$ 带 ${ }^{[12]}$, 具有很高的摩尔消光系数和较高的光电转换效 率 ${ }^{[13]}$, 但在红光/近红光区的吸收较弱. 酞菁类染料在 $600 \sim 750 \mathrm{~nm}$ 处有很强的 $\mathrm{Q}$ 带吸收, 具有很高的摩尔消 光系数 ${ }^{[14]}$, 且原料来源广泛、稳定性好、化学可变性大, 这些优势使其在 DSSC 中占有重要的位置. 但其吸收谱 带稍窄，并且易聚集，影响酞菁光电转换效率.

对酞菁类染料的研究大多以对称结构的单核金属 酞菁类化合物为主 ${ }^{[15]}$, 有关双核金属酞菁的合成较少. 双核酞菁具有更大的共轭结构和较多的 $\pi$ 电子，两个酞

*E-mail: zhangxuejun@nuc.edu.cn

Received August 11, 2015; revised September 2, 2015; published online September 15, 2015.

Project supported by the National Natural Science Foundation of China (No. 51272239), the National Natural Science Foundation of Shanxi Province (No. 2015011011) and the Shanxi Scholarship Council of China (No. 2015-078).

国家自然科学基金(No. 51272239)、山西省自然科学基金(No. 2015011011)和山西省回国留学人员科研(No. 2015-078)资助项目 
菁环之间通过桥连基团能更好地电子传递 ${ }^{[16]}$. 与单核 酞菁类化合物相比，双核酞菁类化合物有更丰富的电化 学行为. 香豆素类染料拥有较大的共轭面以及较强的供 电子能力, 作为敏化剂其本身具有许多优良的性质 ${ }^{[11]}$. 将酞菁与香豆素相连可以扩宽染料的光谱响应范围、增 加共轭程度、提高光电转换效率. 本实验以 1,5 -二羟基 菜、4-硝基邻苯二甲腈、间苯二酚、醋酸锌等为原料, 以 1,8-二氮杂双环 [5.4.0]十一碳-7-烯(DBU)为催化剂合成 中心离子为锌的新型双核酞菁 bi-CPc (Scheme 1). 研究 了其聚集性、稳定性和光物理性质, 利用循环伏安法研 究了 bi-CPc 的电化学性质并计算了其能级结构, 通过进 一步修饰, bi-CPc 有望成为一种性能良好的染料敏化剂.

\section{1 结果与讨论}

\section{1 合成}

通过 1,5-二羟基萘酚与 4-硝基邻苯二甲腈反应得到 前驱体 1 , 菜氧基作为桥连基团引入到酞菁环上. 荎氧 基的引入可以促进唒菁分子间电子的流动. 根据
Knoevenagel 合成法, 间苯二酚和乙酰乙酸乙酯在碱的 催化下，合成 7-差基-4-甲基香豆素(2)，随后将 4-硝基邻 苯二甲腈与化合物 2 反应得到前驱体 3 . 最后将 1,3 以 $1: 6$ 的比例反应, 用柱层析法分离提纯得到 bi-CPc. 香 豆素基团连接在酞菁环外围，可以阻止分子间聚集. 香 豆素类化合物作为一种性能良好的染料敏化剂，其对太 阳光谱有较强的吸收也具有良好的电子传输性能. 基于 此合成得到香豆素双核锌酞菁 bi-CPc.

\section{$1.2 \mathrm{bi}-\mathrm{CPc}$ 的紫外光谱性质与聚集行为研究}

金属酞菁衍生物在紫外光谱中有两个特征吸收, B 带和 $\mathrm{Q}$ 带, B 带由 $\mathrm{a} 2 \mathrm{u}(\pi) \rightarrow \operatorname{eg}\left(\pi^{*}\right)$ 跃迁形成, 在 $300 \mathrm{~nm}$ 附近. Q 带由 $\mathrm{alu}(\pi) \rightarrow \operatorname{eg}\left(\pi^{*}\right)$ 跃迁形成，在 $600 \sim 800 \mathrm{~nm}$ 附近 ${ }^{[17]}$. 图 1 为 bi-CPc 和无取代唒菁锌 $(\mathrm{ZnPc})$ 在 $\mathrm{DMF}$ 溶剂中的紫外光谱图, 浓度分别为 $1 \times 10^{-5}$ 和 $2 \times 10^{-5}$ $\mathrm{mol} / \mathrm{L}$. 图中, bi-CPc 的 Q 带位于 610 和 $677 \mathrm{~nm}$ 处, B 带 位于 281 和 $320 \mathrm{~nm}$ 处, 是典型的酞菁化合物的吸收峰. 与单核酞菁化合物相比, 图中的 B 带明显的加宽增强, 而且在 $400 \sim 470 \mathrm{~nm}$ 处有了光吸收, 这是因为香豆素的

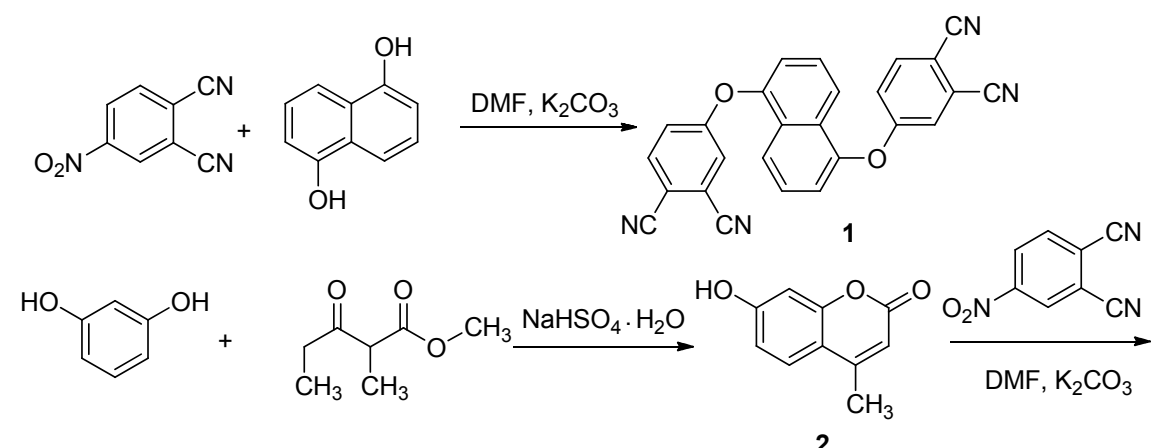<smiles>Cc1cc(=O)oc2cc(Oc3ccc(C#N)c(C#N)c3)ccc12</smiles>

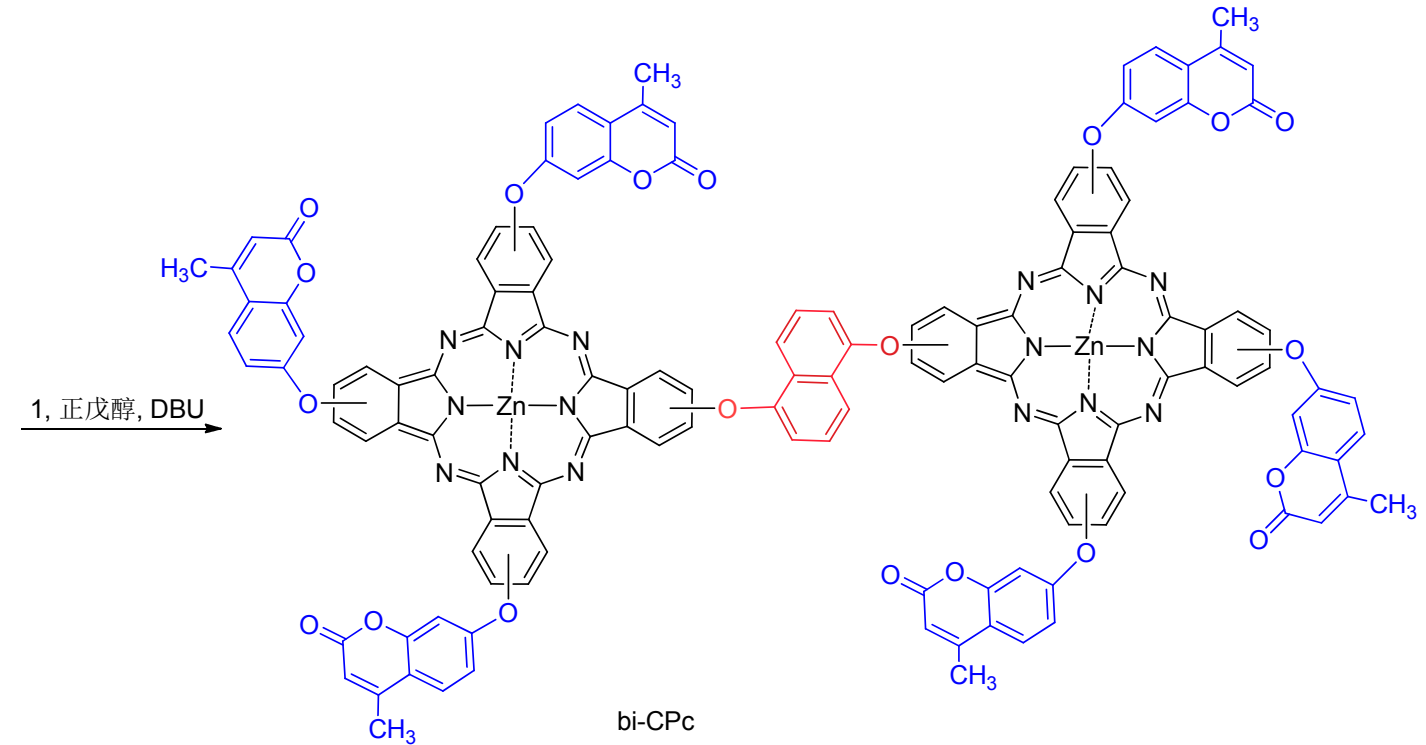

图式 1 bi-CPc 的合成路线

Scheme 1 The synthetic route of bi-CPc 


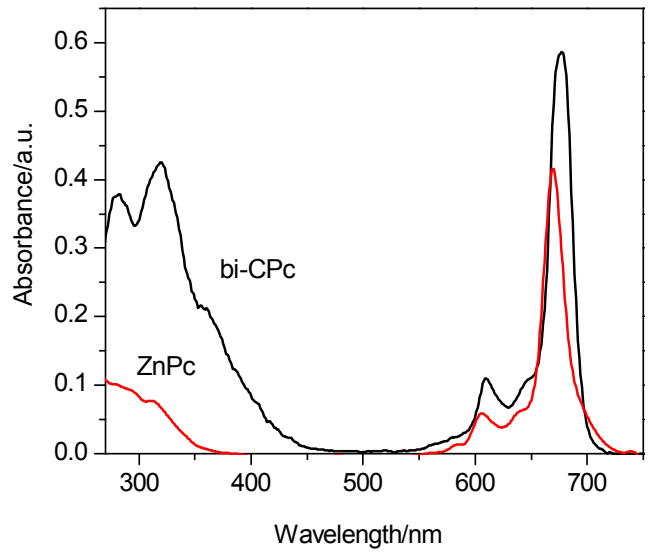

图 1 bi-CPc 和 $\mathrm{ZnPc}$ 紫外光谱图

Figure 1 UV-Vis absorption spectra for bi-CPc and $\mathrm{ZnPc}$

$\pi-\pi^{*}$ 电子跃迁吸收位于 $410 \mathrm{~nm}$ 附近 ${ }^{18]}$; 另外, bi-CPc 的 最大吸收波长位于 $677 \mathrm{~nm}$ 处, 与 $\mathrm{ZnPc}$ 的最大吸收波长 $\lambda_{\text {max }}=667 \mathrm{~nm}^{[19]}$ 相比红移了 $10 \mathrm{~nm}$. 这是因为桥联基团 中的萗环和 7-羟基-4-甲基香豆素取代基团中的苯环会 与酞菁环发生共轭, 而且两个酞菁环的存在会进一步提 高了分子的共轭程度, 使得分子内电子的流动性增强, 其电子激发所需能量在一定程度上降低, 即 $E_{\mathrm{g}}=$ $E_{\mathrm{LUMO}}-E_{\mathrm{HOMO}}$ 会减小, 表现在 UV-Vis 光谱中便是光谱 吸收出现红移.

我们配制了六种不同浓度的 bi-CPc 的 DMF 溶液, 浓度从 $0.1 \times 10^{-5} \sim 1 \times 10^{-5} \mathrm{~mol} / \mathrm{L}$, 并测定各自的吸收 光谱, 见图 2. 考察 bi-CPc 在 DMF 溶液中聚集程度, 见 表 1.

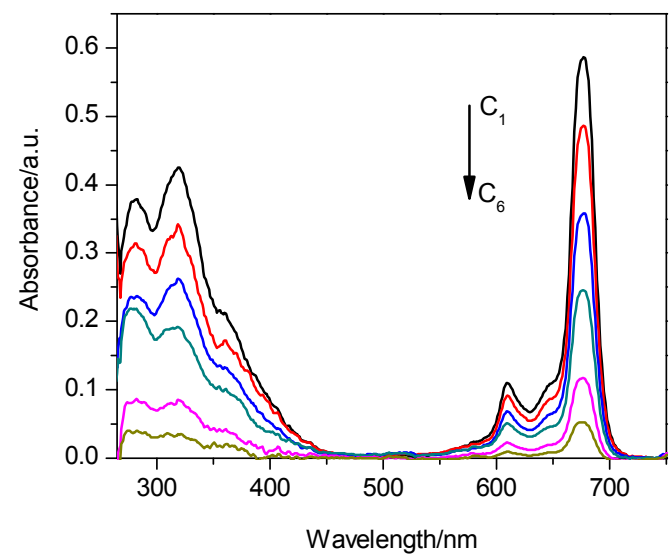

图 2 bi-CPc 在 DMF 中不同浓度的吸收光谱

Figure 2 Absorption spectra of bi-CPc in DMF

从表 1 的数据可以看出在 $0.1 \times 10^{-5} \sim 1.0 \times 10^{-5}$ $\mathrm{mol} / \mathrm{L}$ 浓度范围内, 溶液的摩尔吸光系数 $\varepsilon$ 未发现较大 的明显的线性变化, 这说明在这一浓度范围内 bi-CPc 在 DMF 中主要以单体的形式存在而不发生聚集. 这可能
表 1 不同浓度的 bi-CPc 的 DMF 溶液的光谱性质 Table 1 Spectral property of bi-CPc in DMF $\left(\lambda_{\max }=677 \mathrm{~nm}\right)$

\begin{tabular}{|c|c|c|c|}
\hline 序号 & $c /\left(10^{-5} \mathrm{~mol} \cdot \mathrm{L}^{-1}\right)$ & 吸光度 $A$ & $\begin{array}{c}\text { 摩尔吸光度 } \varepsilon / \\
\left(10^{5} \mathrm{~L} \cdot \mathrm{mol}^{-1} \cdot \mathrm{cm}^{-1}\right)\end{array}$ \\
\hline $\mathrm{C}_{1}$ & 1.0 & 0.586 & 0.5862 \\
\hline $\mathrm{C}_{2}$ & 0.8 & 0.486 & 0.6073 \\
\hline $\mathrm{C}_{3}$ & 0.6 & 0.358 & 0.5971 \\
\hline $\mathrm{C}_{4}$ & 0.4 & 0.246 & 0.6045 \\
\hline $\mathrm{C}_{5}$ & 0.2 & 0.117 & 0.5840 \\
\hline $\mathrm{C}_{6}$ & 0.1 & 0.053 & 0.5870 \\
\hline
\end{tabular}

是由于 bi-CPc 之间外围香豆素基团的空间位阻降低了 酞菁分子之间的 $\pi-\pi$ 相互作用，且增大了分子之间距离 而使化合物不易发生聚集.

\section{3 bi-CPc 热稳定性能研究}

染料敏化剂吸附于 $\mathrm{TiO}_{2}$ 半导体薄膜表面, 其热稳 定性非常重要. bi-CPc 的热稳定性能通过热重分析 (TGA)进行测试, 图 3 是 bi-CPc 的 TGA 曲线, 其加热速 率为 $10{ }^{\circ} \mathrm{C} / \mathrm{min}$, 整个过程在 $\mathrm{N}_{2}$ 保护下进行.

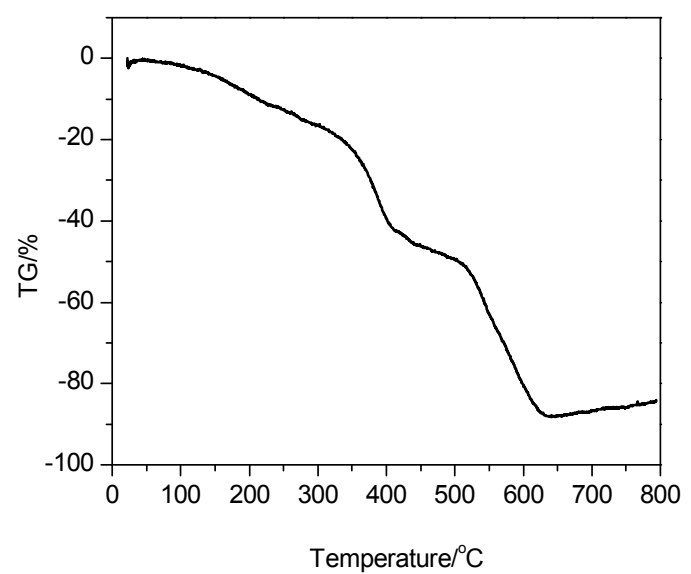

图 $3 \mathrm{bi}-\mathrm{CPc}$ 的热重分析曲线

Figure 3 TGA curves of bi-CPc

如图 3 所示, 化合物在当温度达到 $200{ }^{\circ} \mathrm{C}$ 时轻微分 解, 可能是香豆素取代基的初步分解; 当温度达到 $310{ }^{\circ} \mathrm{C}$ 时, 香豆素取代基分解速度加快; 当温度达到 $420{ }^{\circ} \mathrm{C}$ 时, 对应的是双核酞菁桥连基团的分解、锌原子 与酞菁之间的化学键断裂以及构成酞菁环的化学键开 始断裂; 当温度达到 $639{ }^{\circ} \mathrm{C}$ 时, 相应的损失重量为 $90 \%$ ，对应的是目标产物化合物分解完全. 目标产物的 热稳定性良好, 其分解曲线也与化合物的结构特征相符 合.

\section{$1.4 \mathrm{bi}-\mathrm{CPc}$ 的电化学性质}

利用循环伏安法研究 bi-CPc 的能带结构, 计算其能 级是否与 $\mathrm{TiO}_{2}$ 导带能级相匹配. 图 4 为 bi-CPc 在 $\mathrm{DMF}$ 溶液中的循环伏安曲线, 该溶液是以过氯酸四丁基铵 (浓度为 $0.1 \mathrm{~mol} / \mathrm{L}$ ) 为电解质的 $\mathrm{DMF}$ 溶液, 浓度为 $1 \times$ 
$10^{-5} \mathrm{~mol} / \mathrm{L}$, 以甘录电极 $(\mathrm{SCE})$ 作为参比电极, 两个铂电 极分别为对电极和工作电极, 检测是在无氧环境下进行 的.

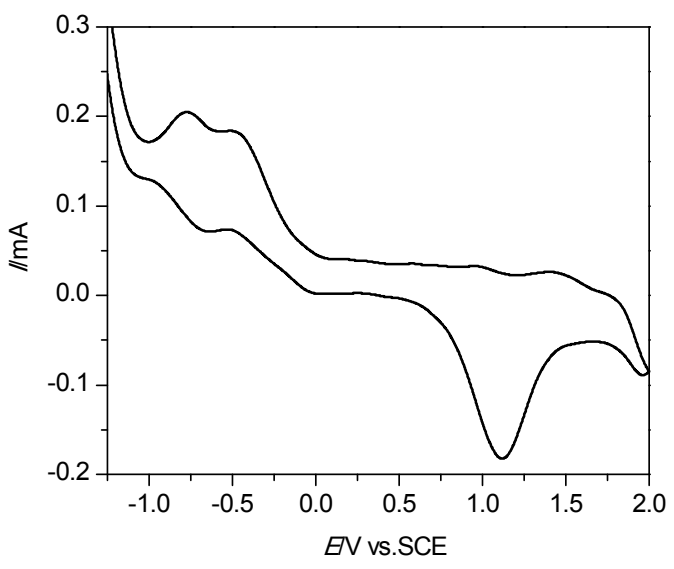

图 4 bi-CPc 的循环伏安图

Figure 4 Cyclic voltammogram for bi-CPc

对染料敏化剂而言, 染料的最低空轨道(LUMO)和 最高占有轨道(HOMO) 是评判其是否适合用于 DSSC 的 重要依据 ${ }^{[20]}$. bi-CPc 的 LUMO 和 HOMO 能级依据 Leeuw 报道的公式进行计算 ${ }^{[21]}$ :

$$
\begin{aligned}
& E_{\mathrm{LUMO}}=-\left(E_{\mathrm{Onset} \rightarrow \mathrm{SCE}}^{\mathrm{Red}}+4.4 \mathrm{eV}\right) \\
& E_{\mathrm{HOMO}}=-\left(E_{\text {onset } \rightarrow \mathrm{SCE}}^{\mathrm{Oxy}}+4.4 \mathrm{eV}\right)
\end{aligned}
$$

其中 $E_{\text {onset } \rightarrow \mathrm{SCE}}^{\mathrm{Red}}$ 和 $E_{\mathrm{onset} \rightarrow \mathrm{SCE}}^{\mathrm{Oxy}}$ 分别为起始还原电位和起始 氧化电位.

由图中可以得出起始氧化电位 $E_{\mathrm{onset} \rightarrow \mathrm{SCE}}^{\mathrm{Oxy}}=0.58 \mathrm{eV}$, 起始还原电位 $E_{\mathrm{Onset} \rightarrow \mathrm{SCE}}^{\mathrm{Red}}=-1.21 \mathrm{eV}$. 将 $E_{\mathrm{onset} \rightarrow \mathrm{SCE}}^{\mathrm{Oxy}}$ 值带 入(2)式计算可得 $E_{\mathrm{HOMO}}=-4.98 \mathrm{eV}$, 将起始还原电位值 带入公式(1)可得 $E_{\mathrm{LUMO}}=-3.19 \mathrm{eV} . \mathrm{TiO}_{2}$ 的导带能级为 $-3.9 \mathrm{eV}, \mathrm{bi}-\mathrm{CPc}$ 的 LUMO 能级高于 $\mathrm{TiO}_{2}$ 导带能级, 这 样可以确保电子能够有效注入 $\mathrm{TiO}_{2}$ 导带. 氧化还原电 对 $\mathrm{I}^{-} / \mathrm{I}_{3}^{-}$能级为 $-4.6 \mathrm{eV}, \mathrm{bi}-\mathrm{CPc}$ 的 HOMO 能级低于氧 化还原电对能级, 可以保证注入电子后形成的氧化态敏 化剂能够获得电子而迅速恢复. 图 5 是 bi-CPc 的能级分 布图, 由图 5 看出 bi-CPc 能够满足与电极能级以及电解 质能级匹配这一要求, 可以实现电子从电解质到 bi-CPc 再到 $\mathrm{TiO}_{2}$ 半导体的注入和转移, 最终实现在外电路的 运输. 这样就初步证实了 bi-CPc 作为太阳能电池敏化染 料的可行性.

\section{2 结论}

采用 DBU 催化法合成了 7-羟基-4-甲基香豆素为取 代基, 1,5-二羟基萗为桥连基团的双核锌酞菁 bi-CPc, 其 拥有较好的稳定性. 将两种染料敏化剂连接起来的新型 双核酞菁在一定程度上扩宽了光谱响应范围, 降低了

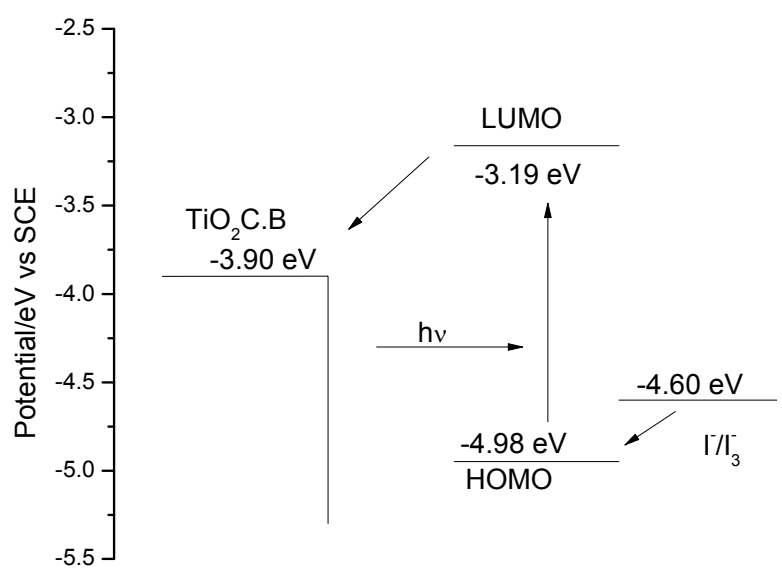

图 5 bi-CPc 能级分布图

Figure 5 Energy level diagram for bi-CPc

$\pi-\pi$ 所需能量, 紫外吸收光谱中产生较大红移. 由于双 核酞菁大的共轭体系以及香豆素基团空间位阻使其表 现出良好的溶解性. bi-CPc 的能级符合 $\mathrm{TiO}_{2}$ 导带能级匹 配要求, 引入羧基等吸附基团后, 有望成为性能良好的 染料敏化太阳能电池的敏化剂.

\section{3 实验部分}

\section{1 仪器与试剂}

紫外-可见分光光度计: UV-2300, 上海天美有限责 任公司; 核磁共振仪: $400 \mathrm{MHz}$ AVANCEIII型, 瑞士 Bruker 公司; 红外光谱仪: FI-TR 4800S, 日本岛津研究 所; CHI 电化学分析仪: LK2005A, 天津市兰力科化学电 子高科技有限公司.

4-硝基邻苯二甲腈(石家庄埃法化学科技有限公司); 1,5 -二羟基萗、乙酰乙酸乙酯、 1,8 -二氮杂双环 $[5,4,0]$ 十 一烯-7 (DBU)、间苯二酚(上海晶纯生化科技股份有限公 司); $N, N$ 二甲基甲酰胺(DMF)、正戊醇、醋酸锌、无水 碳酸钾(天津市光复精细化工研究所), 以上试剂均为分 析纯.

\section{2 实验方法}

\subsubsection{1,5-二[4-(1, 2-二腈基)苯氧基 $]$ 蔡(1)的合成}

将4-硝基邻苯二甲腈 $1.80 \mathrm{~g}$ (10.4 mmol)和 1, 5-二羟 基菜酚 $0.80 \mathrm{~g}(5 \mathrm{mmol})$ 加入三口瓶中, 倒入 $25 \mathrm{~mL}$ 的 DMF, 待全部溶解后, 加入无水 $\mathrm{K}_{2} \mathrm{CO}_{3} 2.00 \mathrm{~g}$ (14 $\mathrm{mmol}$ ), 在 $\mathrm{N}_{2}$ 的保护下, $70{ }^{\circ} \mathrm{C}$ 反应 $32 \mathrm{~h}$. 反应结束后, 将混合物倒入冰水中, 用玻璃棒搅拌 $30 \mathrm{~min}$, 析出沉淀, 抽滤，并用乙醇， $\mathrm{pH}<10$ 的 $\mathrm{NaOH}$ 溶液，水依次洗涤滤 饼, 无水乙醇重结晶, 干燥后得产品 $1.50 \mathrm{~g}$, 产率 $72 \%$. 浅灰色固体, m.p. $267{ }^{\circ} \mathrm{C} ;{ }^{1} \mathrm{H}$ NMR (DMSO- $d_{6}, 400$ MHz) $\delta$ : $6.67(\mathrm{~d}, J=8.0 \mathrm{~Hz}, 2 \mathrm{H}), 7.23(\mathrm{t}, J=8.0 \mathrm{~Hz}, 2 \mathrm{H})$, $7.35 \sim 7.38(\mathrm{~m}, 4 \mathrm{H}), 7.65(\mathrm{~d}, J=8.0 \mathrm{~Hz}, 4 \mathrm{H})$; IR $(\mathrm{KBr}) v$ : 
$2232(\mathrm{CN}), 1247(\mathrm{C}-\mathrm{O}), 1595,1484,1399(\mathrm{C}=\mathrm{C}) \mathrm{cm}^{-1}$. Anal. calcd for $\mathrm{C}_{26} \mathrm{H}_{12} \mathrm{~N}_{4} \mathrm{O}_{2}$ : C 75.73, H 2.91, N 13.59; found C 75.88, H 2.92, N 13.54.

\section{2 .27 -羟基-4-甲基香豆素(2)的合成}

称取 $6.6 \mathrm{~g}(0.06 \mathrm{~mol})$ 间苯二酚放入三口瓶中, 再加 入 $12 \mathrm{~mL}$ 乙酰乙酸乙酯, 加入 $\mathrm{NaHSO}_{4} \cdot \mathrm{H}_{2} \mathrm{O} 8.6 \mathrm{~g}(0.06$ $\mathrm{mol}$ )作为催化剂, 将三口瓶置于油浴中, $100{ }^{\circ} \mathrm{C}$ 反应 $4 \mathrm{~h}$. 反应结束后, 自然冷却 $5 \mathrm{~min}$, 抽滤, 用水洗涤, 将滤饼 自然晾干. 无水乙醇重结晶, 得黄色固体. 产量 $3.84 \mathrm{~g}$, 产率 37\%. m.p. $174{ }^{\circ} \mathrm{C} ;{ }^{1} \mathrm{H}$ NMR (DMSO- $d_{6}, 400 \mathrm{MHz}$ ) $\delta: 2.4(\mathrm{~s}, 3 \mathrm{H}), 6.23(\mathrm{~s}, 1 \mathrm{H}), 6.62 \sim 6.76(\mathrm{~m}, 3 \mathrm{H}), 10.38(\mathrm{~s}$, 1H); IR (KBr) v: $3247(\mathrm{O}-\mathrm{H}) ; 1680(\mathrm{C}=\mathrm{O}) \mathrm{cm}^{-1}$. Anal. calcd for $\mathrm{C}_{10} \mathrm{H}_{8} \mathrm{O}_{3}$ : C 68.10, $\mathrm{H}$ 4.54; found $\mathrm{C} 67.90, \mathrm{H}$ 4.55 .

\subsubsection{4-(4-甲基-7-香豆素氧基)邻苯二甲腈(3)的合成}

将 7-羟基-4-甲基香豆素 $1.76 \mathrm{~g}(10 \mathrm{mmol})$, 4-硝基邻 苯二甲腈 $1.75 \mathrm{~g}(10 \mathrm{mmol})$, 溶解于 $20 \mathrm{~mL} \mathrm{DMF}$ 中, 固 体全部溶解后, 加入无水 $\mathrm{K}_{2} \mathrm{CO}_{3} 2.00 \mathrm{~g}(14 \mathrm{mmol}), \mathrm{N}_{2}$ 保 护下, $60{ }^{\circ} \mathrm{C}$ 搅拌反应 $24 \mathrm{~h}$. 反应结束后, 将混合物倒入 冰水中, 搅拌 $30 \mathrm{~min}$, 静置, 析出沉淀后, 抽滤, 真空干 燥. 用无水乙醇进行重结晶, 得棕色固体. 得产品 2.09 $\mathrm{g}$, 产率 67\%. m.p. $234{ }^{\circ} \mathrm{C} ;{ }^{1} \mathrm{H}$ NMR (DMSO- $d_{6}, 400$ $\mathrm{MHz}) \delta: 2.4(\mathrm{~s}, 3 \mathrm{H}), 6.23(\mathrm{~s}, 1 \mathrm{H}), 7.02 \sim 7.04(\mathrm{~m}, 2 \mathrm{H})$, $7.58 \sim 7.67(\mathrm{~m}, 2 \mathrm{H}), 7.94 \sim 8.16(\mathrm{~m}, 3 \mathrm{H})$; IR $(\mathrm{KBr}) v: 2231$ $(\mathrm{CN}), 1259(\mathrm{C}-\mathrm{O}), 1733(\mathrm{C}=\mathrm{O}), 1624,1589,1489(\mathrm{C}=$ C) $\mathrm{cm}^{-1}$. Anal. calcd for $\mathrm{C}_{18} \mathrm{H}_{10} \mathrm{~N}_{2} \mathrm{O}_{3}$ : C 71.45, $\mathrm{H} 3.30, \mathrm{~N}$ 9.26; found C 71.23, H 3.31, N 9.28.

\section{$3.2 .49(10), 16(17), 23(24)-$ 三 [4- 甲基-7-香豆素氧} 基]-2(3)-(1,5-二氧基䓠)双核锌酞菁(bi-CPc)的合成

将化合物 1 和 3 按 $1: 6$ 的比例混合, 其中化合物 1 $0.26 \mathrm{~g}(0.5 \mathrm{mmol})$, 化合物 $30.91 \mathrm{~g}$, (3 mmol), 再称量 $0.275 \mathrm{~g}(1.2 \mathrm{mmol})$ 醋酸锌一起置于三口烧瓶中, 加入 45 $\mathrm{mL}$ 的正戊醇作溶剂, 边搅拌边加入 $1.5 \mathrm{~mL} \mathrm{DBU}$, 在 $\mathrm{N}_{2}$ 的保护下, 并将温度调整到 $150{ }^{\circ} \mathrm{C}$, 反应 $30 \mathrm{~h}$. 反应完 毕后, 冷却至室温, 倒入 $100 \mathrm{~mL}$ 的甲醇, 静置 $30 \mathrm{~min}$, 析出沉淀, 抽滤, 并用甲醇, 水依次清洗, 滤饼在真空 下进行干燥, 得粗品. 按 $V$ (二氯甲烷) $: V$ (四氢呋喃 $)$ : $V($ 氯仿 $)=3: 1: 1$ 的比例配置洗脱液, 将粗品进行柱层 析分离提纯, 得到墨绿色固体 $0.32 \mathrm{~g}$, 产率 $22 \%$. m.p.> $300{ }^{\circ} \mathrm{C}$; ${ }^{1} \mathrm{H}$ NMR (DMSO- $\left.d_{6}, 400 \mathrm{MHz}\right) \delta: 1.25 \sim 1.59$ (s, 18H, $\alpha-\mathrm{C}-\mathrm{H}), 7.35$ (s, 6H, ArH), 7.74 (s, 12H, ArH), 7.84 (s, 8H, ArH), 7.95 (d, $J=8.0 \mathrm{~Hz}, 12 \mathrm{H}, \operatorname{ArH}), 8.11$ (d, $J=$ $8.0 \mathrm{~Hz}, 12 \mathrm{H}, \mathrm{ArH}), 8.29 \sim 8.32(\mathrm{~m}, 4 \mathrm{H}, \mathrm{ArH}), 8.50(\mathrm{~s}, 2 \mathrm{H}$, $\mathrm{ArH})$; IR (KBr) v: 1606, $1469(\mathrm{C}=\mathrm{N}), 1726(\mathrm{C}=\mathrm{O})$,
1271, $1072(\mathrm{C}-\mathrm{O}-\mathrm{C}), 740,858(\mathrm{C}-\mathrm{H}) \mathrm{cm}^{-1}$. Anal. calcd for $\mathrm{C}_{135} \mathrm{H}_{74} \mathrm{~N}_{16} \mathrm{O}_{20} \mathrm{Zn}_{2}$ : C 68.35, H 3.12, N 9.44; found C 68.48, H 3.12, N 9.41.

辅助材料(Supporting Information) 最终产物的 IR 以及 ${ }^{1} \mathrm{H}$ NMR 谱图. 这些材料可以免费从本刊网站 (http://sioc-journal.cn/)上下载.

\section{References}

[1] O’Regan, B.; Grätzel, M. Nature 1991, 353, 737

[2] Grätzel, M. J. Photochem. Photobiol. A 2004, 164, 34

[3] He, J.-J.; Chen, Y.-S.; Wang, T.-T.; Zeng, H.-P. Org. Chem. 2012, 32, 472 (in Chinese). (何俊杰，陈舒欣，王婷婷，曾和平，有机化学， 2012，32, 472.)

[4] Hou, Y.-J.; Xie, P.-H.; Zhang, B.-W.; Cao, Y.; Xiao, X.-R.; Wang, W.-B. Inorg. Chem. 1999, 38, 6320.

[5] Horiuchi, T.; Miura, H.; Uchida, S. J. Photochem. Photobiol. A: Chem. 2004, 164, 29.

[6] Hara, K.; Kurashige, M.; Ito, S.; Shinpo, A.; Suga, S.; Sayama, K.; Arakawa, H. Chem. Commun. 2003, 252.

[7] Karthikeyan, C. S.; Peter, K.; Wietasch, H.; Thelakkat, M.; Energy, M. Sol. Cells 2007, 91, 432.

[8] Hara, K.; Sayama, K.; Ohga, Y.; Shinpo; Suga, S.; Arakawa, H. Chem. Commun. 2001, 569.

[9] Kitamura, T.; Ikeda, M.; Shigaki, K.; Inoue, T.; Andenson, N. A.; Ai, X.; Lian, T. Q.; Yanagida, S. Chem. Mater. 2004, 16, 1806.

[10] Hwang, S.; Lee, J. H.; Park, C.; Lee, H.; Kim, C.; Lee, M. H.; Lee, W.; Paka, J.; Kim, K.; Park, N. G.; Kim, C. Chem. Commun. 2007, 4887.

[11] Hara, K.; Miyamoto, K.; Abe, Y.; Yanagida, M. J. Phys. Chem. B 2005, 109, 23776.

[12] Wang, Y.-Q.; Lu, X.; Wei, X.-D.; Wu, W.-J.; Xie, Y.-S. New J. Chem. 2014, 38: 3227.

[13] Mathew, S.; Yella, A; Gao, P.; Humphry-Baker, R. Nat. Chem. 2014, 6, 242

[14] Takuro, L.; Hirotaka, N.; Naruhiko, M.; Matthew, J. G.; Shogo, M.; Mutsumi, K. Chem. Commun. 2014, 50, 1941.

[15] Mao, L.-J.; Tan, Q.-L.; Xing, G.-Q.; Han, M.-L.; Zhang, X.-J. Chin. J. Org. Chem. 2012, 32, 2315 (in Chinese).

(毛利军, 谭青龙, 新冠琼, 韩明亮, 张学俊, 有机化学, 2012, 32, 2315.)

[16] Kc, C. C.; Stranius, K.; Dsouza, P. J. Chem. Phys. 2013, 117, 763.

[17] Camur, M.; Ahsen, V.; Durmus, M. Photochem. Photobiol. A: Chem. 2011, 219, 217.

[18] Han, L.; Zhou, X.; Ye, Q.; LI, J.-Y.; Gao, J.-R. Chin. J. Org. Chem. 2013, 33, 1000 (in Chinese). (韩亮, 周雪, 叶青, 李郁绵, 高建荣, 有机化学, 2013, 33, 1000.)

[19] Peng, Y.-R.; Huang, F.-H. Strait Pharm. J. 2003, 15, 53 (in Chinese). (彭亦如, 黄风华, 海峡药学, 2003, 15, 53.)

[20] Han, M.-L. M.S. Thesis, North University of China, Taiyuan, 2015 (in Chinese). (韩明亮, 硕士论文, 中北大学, 太原, 2015.)

[21] Leeuw, D. M.; Simenon, M. M. J.; Brown, A. R. Synth. Met. 1997, 87,53 . 